\title{
Using Models and Data to Support Optimization of the Military Health System: A Case Study in an Intensive Care Unit
}

\author{
BRIAN J. MASTERSON \\ Wilford Hall Medical Center \\ THOMAS G. MIHARA \\ Center for Health Care Management Studies, Office of the Assistant Secretary of Defense, Health Affairs $(O A S D(H A))$, \\ TRICARE Management Activity (TMA), Falls Church, VA, USA
}

\author{
GEORGE MILLER* * STEPHEN C. RANDOLPH, M. EMMA FORKNER and ANDREW L. CROUTER \\ The Altarum Institute, PO Box 134001, Ann Arbor, MI 48113-4001, USA \\ E-mail: george.miller@altarum.org
}

\begin{abstract}
Optimizing healthcare delivery - improving processes to reduce impediments to care - is an important goal of the Military Health System. Models and data can be effective tools to assist managers in achieving this goal. This paper illustrates this utility with a case study of the intensive care unit (ICU) at the US Air Force's Wilford Hall Medical Center. A discrete-event simulation demonstrates how the integration of corporate data and ICU data through a model can help identify changes intended to improve ICU performance. Results of the analysis describe impacts of ICU size and bed mix, operating policies, and the deployment of ICU staff on measures of occupancy, congestion, and physician training needs.
\end{abstract}

Keywords: intensive care unit, simulation, bed occupancy, operating policies, congestion

\section{Introduction}

The Military Health System (MHS) has begun to focus on optimization of healthcare delivery at all facilities. This effort has concentrated on improving processes in order to reduce impediments to care. Understanding the interrelationships among patient management pathways, facility design, and staffing can help achieve these optimization goals by providing a basis for modifying these system characteristics so that they interact effectively. Recognizing that model-based analysis can enhance such understanding, the US Congress [1] has encouraged the Department of Defense (DoD) to evaluate simulation modeling in terms of validity and usefulness for developing and implementing new ways of improving healthcare outcomes.

Due to both the importance of outcomes and resource intensity, multiple improvement opportunities exist in the intensive care environment. Across this country, $8 \%$ of inpatient admissions are to intensive care units (ICUs). Yet these account for nearly $30 \%$ of expenditures [2]. The MHS must balance access to the intensive care environment with an opportunity for military healthcare providers to maintain skills necessary to complete missions related to delivery of care in wartime or other contingencies. Simulation modeling can help achieve this balance.

Models of health services require accurate data that describe the demand for the services depicted in the models. In this case, demand is characterized by the demographics,

* Corresponding author. diagnosis, acuity of illness, and resource utilization by each patient. To accommodate department-level goals, such data must frequently be collected at the unit level. Through their data requirements, models can help focus data collection efforts on information needed to establish metrics that a manager must use to improve care. Model and data development and use thus can be mutually supporting, with models identifying important data requirements and data providing inputs that make models useable.

Wilford Hall Medical Center (WHMC) is a 275-bed trauma center and one of only two level-1 trauma centers within the DoD. Located in San Antonio (Texas), WHMC is affiliated with a university healthcare system through a trauma consortium. This consortium provides a broad spectrum of care to eligible military beneficiaries and trauma care to all citizens of south Texas. Because of limited ICU resources, these facilities sometimes close to ambulance traffic through a diversion process. Diverting patients leads to wasted time when minutes could mean the difference between life and death. Preparing for future expansion of the critical care environment at WHMC requires an accurate assessment of the demand for these services and the capability of the ICU to meet this demand. Because of the complexity of the healthcare system, a model was needed to help analyze different patient loads, ICU sizes, and ICU operating policies that would impact this ability to meet demand. In describing the development and application of this model, this paper provides a case study of the successful use of models and data to support MHS optimization. 
The remainder of this paper is organized into four sections. In section 2 , we provide motivation for the study with a discussion of the operation of the ICU and plans for its expansion. Section 3 summarizes the structure of the model, briefly reviews the literature describing similar models, provides some technical details concerning model use, and describes the data used by the model. Section 4 discusses application of the model to investigate alternative ICU sizing options, the impact of ICU operating policies on ICU performance, and ways to mitigate the effects of a major medical deployment on ICU operations. The paper closes with a summary of lessons learned from the study.

\section{Background}

According to Standard Inpatient Data Record (SIDR) data, WHMC reported 15,234 ICU bed days during fiscal year 2002 - the highest volume for any facility in the MHS. The WHMC adult ICU consists of four separate units consisting respectively of medical, surgical, cardiac, and progressive care (PCU or 'stepdown') beds. The first three of these bed types provide a greater intensity of care than the stepdown beds, and are sometimes referred to as 'big beds'. All but the cardiac beds, which are separately located, occupy space on the second floor of the medical center - space that also houses a pediatric ICU. (Because the focus of this study was redesign of the adult ICU, the pediatric unit was not analyzed in this study.) Patients with appropriate care requirements can enter the ICU via any of these bed types (see figure 1), and patients are sometimes moved from one bed type to another if care requirements dictate. A surgical patient, for example, might develop a medical condition requiring a move to a medical bed, or an ICU patient whose condition improves might be moved to a stepdown bed. ICU policies govern the matching of care requirements to bed types for both patient admissions and subsequent patient moves.

Since WHMC has recently been awarded funds to renovate the second floor adult ICU space, a principal purpose of this study was to provide input to the redesign process. A goal of ICU redesign is proper physical sizing. As demonstrated by ICU diversion that can be as high as $56 \%$ of the time in a given month, there is heavy competition for the constrained

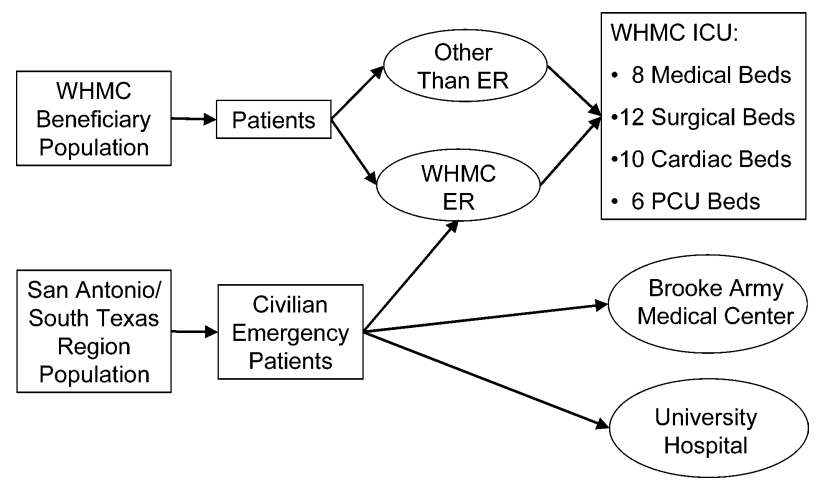

Figure 1. Patient flows into the WHMC adult ICU.
ICU bed resource. These constraints on bed availability are exacerbated by military operational requirements and resulting nursing and other staff deployments, which reduce ICU staff and require temporary closure of some ICU beds. Certification of WHMC as a level-1 trauma center by the American College of Surgeons (ACS) requires that the emergency department be open to trauma patients $95 \%$ of the time. Because high ICU diversion rates threaten this certification, the goal of the WHMC ICU is to be able to accommodate a trauma patient admission $95 \%$ of the time. WHMC's role as a center for graduate medical education (GME) is also impacted by ICU closure - closing the ICU diverts patients who would otherwise provide useful experience to WHMC residents.

This study employed simulation-based analysis to address the hypothesis that proper sizing and operating policies within the ICU will improve ICU performance. The results characterize interactions among the bed configuration, bed availability (as a result of staffing levels that can be impacted by medical deployments), medical and trauma closure polices, and policies for assignment and transfer of patients to medical, surgical, cardiac and stepdown beds. They represent the effects of these constraints and policies on numbers of patients deferred or turned away, bed occupancy rates, availability to accommodate a trauma patient, GME program compliance, and cost and revenue streams. Alternatives were compared primarily by examining tradeoffs between utilization levels (as measured by bed occupancy rates) and access to care (as measured by patients turned away and availability to accommodate a trauma admission). Costs varied little among cases and are therefore not reported here. GME program compliance differed significantly among cases only when considering the effects of a major medical deployment, as discussed in section 4 .

\section{Methodology}

\subsection{The model}

Our approach to this study involved simulating the operations of the WHMC ICU under alternative assumptions about bed availability and ICU policy to develop an understanding of the impact of these characteristics on ICU performance. While queuing models can be used to represent congestion in a service facility of this type, we employed discrete-event simulation to allow a more robust representation of multiple patient types, multiple bed types, and alternative ICU operating policies. We developed the model in the MedModel simulation environment and validated it via successful comparison of model results with historical WHMC ICU performance (see table 1). The model generates a stream of patients desiring admission to the ICU and processes these patients in accordance with simulated patient needs, numbers of available beds by type, and policies for bed utilization. A generalized model design ensured adaptability to other ICU settings.

Model outputs are expressed in terms of numbers of patients by type deferred or turned away, bed occupancy rates, 
contribution to ACS compliance (percent of time the ICU is open to trauma patients), cost and revenue streams, and GME program compliance (see figure 2). This last output measures the extent to which ICU patients support the training requirements of WHMC residents, and is based on an assumption that the current mix of Diagnosis Related Groups (DRGs) being seen in the ICU provides an adequate mix of conditions and procedures for residency training. We then estimate the extent to which each model experiment results in a shortfall from this baseline DRG mix. The sum of these shortfalls of-

Table 1

Model testing.

\begin{tabular}{|c|c|c|}
\hline & Test & Results \\
\hline \multicolumn{3}{|l|}{ Verification } \\
\hline $\begin{array}{l}\text { Logical } \\
\text { verification }\end{array}$ & Logic walkthroughs & Verified \\
\hline Code verification & Operational traces & Verified \\
\hline \multicolumn{3}{|l|}{ Usability } \\
\hline \multirow[t]{2}{*}{ User interface } & User-friendly-evaluation & Accepted \\
\hline & Understandable-evaluation & Accepted \\
\hline Model output & Recognizable-evaluation & Accepted \\
\hline \multicolumn{3}{|l|}{ Face validation } \\
\hline Model output & $\begin{array}{l}\text { Intuitively accurate- } \\
\text { evaluation }\end{array}$ & Accepted \\
\hline \multicolumn{3}{|l|}{ Output validation } \\
\hline Patent arrivals & $t$-test of paired samples & $\begin{array}{l}\text { Same probability } \\
\text { distribution }\end{array}$ \\
\hline Length of stay & Stat::Fit goodness of fit & Accepted \\
\hline Patient transfers & Model vs. historical results & Model predictive of history \\
\hline $\begin{array}{l}\text { Beneficiary } \\
\text { categories }\end{array}$ & Model vs. historical results & Model predictive of history \\
\hline Patient type & Model vs. historical results & Model predictive of history \\
\hline Patient mortality & Model vs. historical results & Model predictive of history \\
\hline Closure policy & $95 \%$ confidence interval & Accepted \\
\hline Patient blocking & Model vs. historical results & Model predictive of history \\
\hline
\end{tabular}

fers a crude metric for the extent to which the ICU represented in the experiment supports the WHMC GME program (see table 2). A significant shortfall suggests a degraded ability of WHMC to provide its residents with the full spectrum of patient conditions needed for a thorough training program.

Several simulation models have previously been developed to explore ICU bed requirements or operating policies [2-9]. The study described in this paper is unique in its explicit treatment of the non-patient-care missions of training and deployment that are inherent in MHS operations. It is also unusual in its consideration of constraints on ICU operations, such as those imposed by the ACS and by GME requirements.

Each model experiment conducted in the study involved simulating four weeks (28 days) of ICU operations. Thirty replications of each case were run to guarantee statistical stability of the results. We examined confidence intervals on daily bed census by bed type to ensure that 30 replications were adequate. (A typical 95\% confidence interval is 10.06 to 10.28 for the medical bed census in the base case results reported below. Given such tight confidence intervals, we present only mean results here.) Each replication was preceded by a warm-up period to fill the ICU with an initial patient load. Qualitative review of bed census time histories by day of the week (since patient admission patterns vary by day) was used to provide some assurance that variation in bed use over time had leveled off by the end of the warm-up period. Random number streams representing different random processes were isolated and duplicated in each experiment as a variance reduction technique.

\subsection{Data}

The model employs data that characterize specific resources, policies and operations of the WHMC ICU. In particular, the data are used to describe:

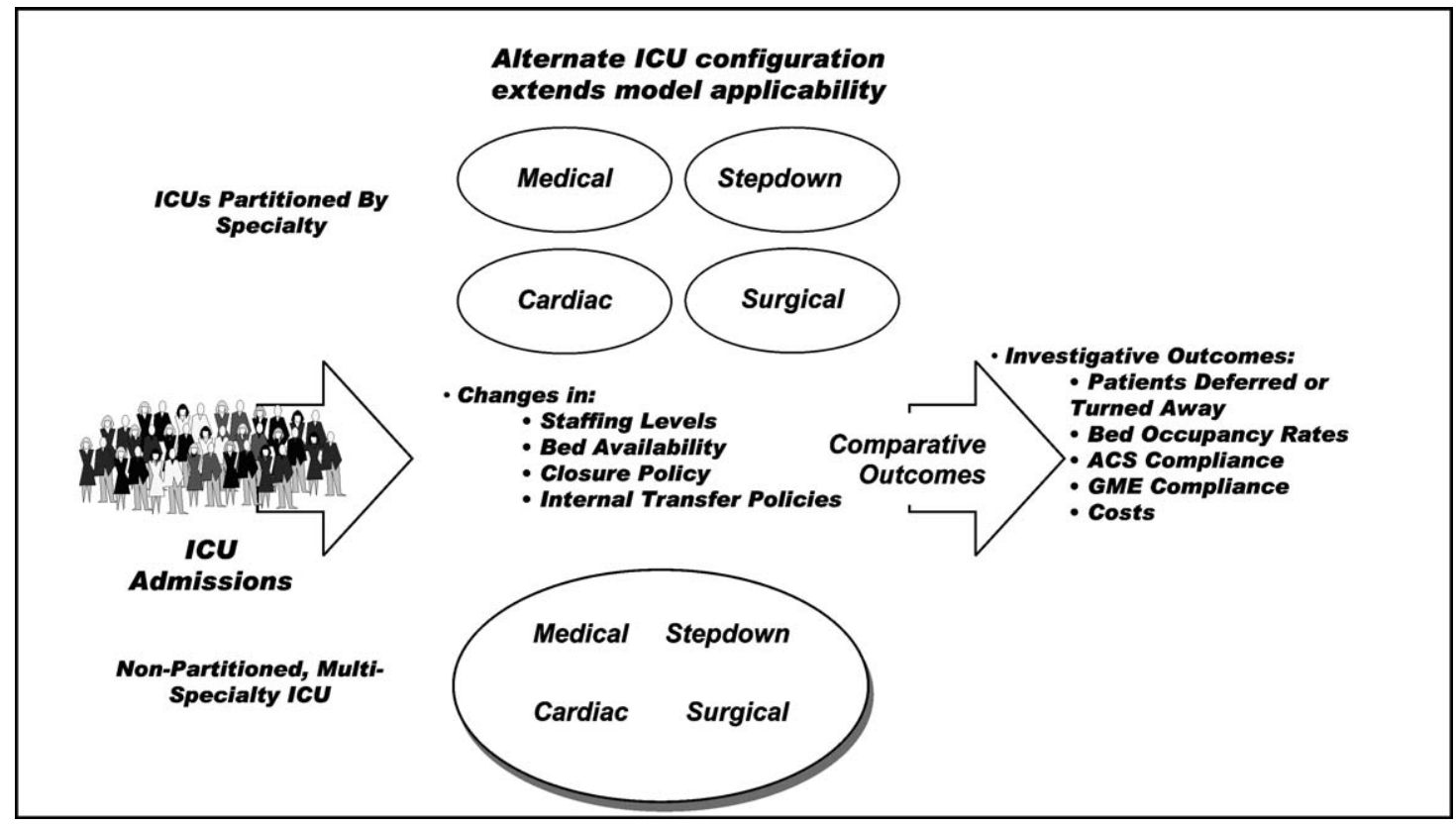

Figure 2. Overview of WHMC ICU model. 
Table 2

Example computation of GME effects.

\begin{tabular}{|c|c|c|c|c|}
\hline \multirow[t]{2}{*}{ Clinical area } & \multirow[t]{2}{*}{ Top ten DRGs } & \multicolumn{2}{|c|}{ Average frequency } & \multirow{2}{*}{$\begin{array}{c}\text { Shortfall } \\
\text { from } \\
\text { current }\end{array}$} \\
\hline & & $\begin{array}{l}\text { Current bed } \\
\text { configuration }\end{array}$ & $\begin{array}{l}\text { Candidate bed } \\
\text { configuration }\end{array}$ & \\
\hline \multirow{10}{*}{ Medicine } & 174: G.I. HEMORRHAGE W CC & 2.4 & 2.2 & 0.2 \\
\hline & 316: RENAL FAILURE & 1.8 & 1.6 & 0.2 \\
\hline & 475: RESPIRATORY SYSTEM DIAGNOSIS WITH VENTILATOR SUPPORT & 1.5 & 1.4 & 0.1 \\
\hline & 14: SPECIFIC CEREBROVASCULAR DISORDERS EXCEPT TIA & 1.8 & 1.8 & 0.0 \\
\hline & 205: DISORDERS OF LIVER EXCEPT MALIG, CIRR, ALC HEPA W CC & 1.1 & 1.0 & 0.1 \\
\hline & 296: NUTRITIONAL \& MISC METABOLIC DISORDERS AGE > 17 W CC & 1.6 & 0.9 & 0.6 \\
\hline & 483: TRACHEOSTOMY EXCEPT FOR FACE, MOUTH \& NECK DIAGNOSES & 1.7 & 1.1 & 0.5 \\
\hline & 175: G.I. HEMORRHAGE W/O CC & 1.3 & 0.9 & 0.4 \\
\hline & Total & 17.7 & & 3.2 \\
\hline & Total shortfall as percent of current DRG mix & & & $18 \%$ \\
\hline \multirow[t]{12}{*}{ Surgical } & 288: O.R. PROCEDURES FOR OBESITY & 2.7 & 2.8 & 0.0 \\
\hline & 5: EXTRACRANIAL VASCULAR PROCEDURES & 2.2 & 2.0 & 0.2 \\
\hline & 303: KIDNEY, URETER \& MAJOR BLADDER PROCEDURES FOR NEOPLASM & 0.8 & 1.0 & 0.0 \\
\hline & 111: MAJOR CARDIOVASCULAR PROCEDURES W/O CC & 1.4 & 1.2 & 0.2 \\
\hline & 498: SPINAL FUSION W/O CC & 1.0 & 0.9 & 0.1 \\
\hline & 478: OTHER VASCULAR PROCEDURES W CC & 0.8 & 0.8 & 0.0 \\
\hline & 191: PANCREAS, LIVER \& SHUNT PROCEDURES W CC & 0.8 & 0.9 & 0.0 \\
\hline & 483: TRACHEOSTOMY EXCEPT FOR FACE, MOUTH \& NECK DIAGNOSES & 1.0 & 0.9 & 0.1 \\
\hline & 148: MAJOR SMALL \& LARGE BOWEL PROCEDURES W CC & 0.7 & 0.7 & 0.0 \\
\hline & 75: MAJOR CHEST PROCEDURES & 0.3 & 0.3 & 0.0 \\
\hline & Total & 11.7 & & 0.6 \\
\hline & Total shortfall as percent of current DRG mix & & & $5 \%$ \\
\hline \multirow[t]{10}{*}{ Cardiac } & 116: OTH PERM CARD PACEMAK IMPL OR PTCA W CORONARY ARTERY STENT IMPLN & 4.0 & 3.6 & 0.4 \\
\hline & 109: CORONARY BYPASS W/O PTCA OR CARDIAC CATH & 2.5 & 2.7 & 0.0 \\
\hline & 516: PERCUTANEOUS CARDIOVASCULAR PROCEDURES W AMI & 2.0 & 2.2 & 0.0 \\
\hline & 143: CHEST PAIN & 2.0 & 1.5 & 0.5 \\
\hline & 124: CIRCULATORY DISORDERS EXCEPT AMI, W CARD CATH \& COMPLEX DIAG & 1.9 & 1.7 & 0.2 \\
\hline & 107: CORONARY BYPASS W CARDIAC CATH & 1.5 & 1.7 & 0.0 \\
\hline & 75: MAJOR CHEST PROCEDURES & 1.4 & 1.3 & 0.1 \\
\hline & 122: CIRCULATORY DISORDERS W AMI W/O MAJOR COMP, DISCHARGED ALIVE & 0.9 & 0.7 & 0.2 \\
\hline & Total & 21.3 & & 1.7 \\
\hline & Total shortfall as percent of current DRG mix & & & $8 \%$ \\
\hline \multirow[t]{12}{*}{ Trauma } & 486: OTHER O.R. PROCEDURES FOR MULTIPLE SIGNIFICANT TRAUMA & 3.0 & 1.9 & 1.1 \\
\hline & 483: TRACHEOSTOMY EXCEPT FOR FACE, MOUTH \& NECK DIAGNOSES & 2.0 & 1.2 & 0.8 \\
\hline & 449: POISONING \& TOXIC EFFECTS OF DRUGS AGE > $17 \mathrm{~W}$ CC & 1.2 & 1.0 & 0.2 \\
\hline & 442: OTHER O.R. PROCEDURES FOR INJURIES W CC & 1.7 & 1.2 & 0.6 \\
\hline & 447: ALLERGIC REACTIONS AGE > 17 & 1.7 & 1.4 & 0.3 \\
\hline & 1: CRANIOTOMY AGE > 17 EXCEPT FOR TRAUMA & 0.8 & 0.8 & 0.0 \\
\hline & 487: OTHER MULTIPLE SIGNIFICANT TRAUMA & 1.5 & 1.4 & 0.1 \\
\hline & 109: CORONARY BYPASS W/O PTCA OR CARDIAC CATH & 1.2 & 0.8 & 0.4 \\
\hline & 75: MAJOR CHEST PROCEDURES & 1.3 & 0.7 & 0.6 \\
\hline & 485: LIMB REATTACHMENT, HIP AND FEMUR PROC FOR MULTIPLE SIGNIFICANT T & 0.9 & 1.0 & 0.0 \\
\hline & Total & 15.3 & & 4.0 \\
\hline & Total shortfall as percent of current DRG mix & & & $26 \%$ \\
\hline
\end{tabular}

- demand for the ICU (patient arrival rates, diagnosis mix, and distributions of length of stay),

- available beds by type (as affected by beds physically present and available staffing),

- policies governing use of the ICU (rules for closure of the ICU to some patient types, bed types to which patients may be admitted, transfer of patients from one bed type to another, etc.), and

- cost and revenue associated with use of the ICU.

The preponderance of the data used in this study was based on historical performance of the ICU as inferred from the MHS SIDR and the WHMC ICU Log database maintained by the 
ICU staff. Data describing bed availability and ICU policies were established via conversations with WHMC staff, and were varied parametrically during the study. The analysis employed three alternative random patient demand streams derived from historical data. (Except for diagnosis mix, historical demand rates did not vary significantly by month, so no seasonal variation in patient arrival rates was represented.) The three streams corresponded to current demand, projected future demand in FY 2015 (developed by these authors in a previous analysis effort [10]), and the demand anticipated in the event of a major medical deployment. (As explained in section 4.4, demand for the ICU declines somewhat during such a deployment.)

The first three rows of table 3 include the average number of patients associated with these three admission patterns for each of four patient types that require admission to big beds. (The actual bed type that a patient of a given type will occupy depends on bed availability and on policy data governing allowable bed types for each patient type.) Each row indicates the mean number of arriving patients per simulated four-week (28-day) period of each ICU patient type. Several experiments employ demand data representing intermediate years that were interpolations between the current and FY 2015 demand rates. In addition, each experiment includes a separate patient stream for admissions to progressive care unit (PCU) beds, with a mean of 27.9 arriving patients. The fourth row of the table summarizes average length of stay results for the four ICU patient types.

Table 3

Summary of patient demand data.

\begin{tabular}{lccccc}
\hline Patient type & Medical & Surgical & Cardiac & Trauma & Total \\
\hline Mean arrivals (2003) & 56.1 & 35.0 & 44.3 & 50.6 & 186 \\
Mean arrivals (2015) & 64.5 & 40.3 & 51.0 & 58.2 & 214 \\
Mean arrivals (Depl) & 46.9 & 35.5 & 42.6 & 34.0 & 159 \\
ALOS (days) & 4.1 & 3.2 & 2.9 & 5.2 & 3.5 \\
\hline
\end{tabular}

While the table summarizes the overall load on the ICU, the actual patient demand patterns simulated in the model are somewhat more complicated than indicated here. Patient arrival rates vary with time of day and day of the week, and lengths of stay depend on characteristics of the patients other than patient type (such as whether the patient will die in the ICU). Based on goodness-of-fit tests, nonstationary Poisson processes characterize patient arrivals, and lognormal distributions fit LOS data. These distributional forms have been observed at a number of other ICUs [11], suggesting the applicability of this model to other settings.

\section{Results}

\subsection{ICU sizing}

ICU sizing experiments addressed establishing the most effective number of beds of each type over time (as the population served by the ICU increases). Analysis of alternative bed configurations assumed that no closure policy will be in effect (so that any ICU patient will be admitted if a big bed is available), and that no bed partitioning will be in effect (so that any ICU patient can occupy any big bed type if the preferred type is unavailable). These assumptions correspond with current operation of the ICU. Their impacts were addressed in subsequent model experiments.

Table 4 summarizes results for some of the bed configurations and scenarios for future years. The base case represents the current configuration. Options 1 and 2 are examples of configurations that could be realized via the already funded renovation of the ICU. Option 3 is an example of a configuration that could be achieved by relocating the pediatric ICU and using the vacated space for more adult beds. (As noted earlier, reconfiguration of the pediatric ICU was not addressed in this study; this option assumes that the relocated pediatric unit would retain its current size.) Option 4

Table 4

Illustrative ICU sizing results.

\begin{tabular}{|c|c|c|c|c|c|c|c|c|c|c|}
\hline \multirow[t]{2}{*}{ Case } & \multirow{2}{*}{$\begin{array}{c}\text { Bed } \\
\text { configuration } \\
\text { Year }\end{array}$} & \multicolumn{2}{|c|}{$\begin{array}{c}\text { Base (current bed } \\
\text { configuration) }\end{array}$} & \multirow{2}{*}{$\begin{array}{c}\text { Option } 1 \text { (fewer PCU, } \\
\text { more ICU beds) }\end{array}$} & \multicolumn{2}{|c|}{$\begin{array}{c}\text { Option } 2 \text { (no PCU, } \\
\text { all ICU beds) }\end{array}$} & \multicolumn{2}{|c|}{$\begin{array}{c}\text { Option } 3 \text { (relocate } \\
\text { pediatric ICU) }\end{array}$} & \multicolumn{2}{|c|}{$\begin{array}{c}\text { Option } 4 \text { (new } \\
\text { construction) }\end{array}$} \\
\hline & & 2003 & 2015 & & 2003 & 2007 & 2003 & 2015 & 2003 & 2015 \\
\hline \multirow[t]{4}{*}{ Available beds } & Medical & 8 & 8 & 11 & 14 & 14 & 14 & 14 & 14 & 14 \\
\hline & Surgical & 12 & 12 & 12 & 12 & 12 & 14 & 14 & 12 & 12 \\
\hline & Caridac & 10 & 10 & 10 & 10 & 10 & 10 & 10 & 10 & 10 \\
\hline & PCU & 6 & 6 & 3 & 0 & 0 & 6 & 6 & 6 & 6 \\
\hline \multirow[t]{5}{*}{ Bed occupancy rates } & Medical & $87.1 \%$ & $89.5 \%$ & $81.2 \%$ & $74.6 \%$ & $77.8 \%$ & $70.1 \%$ & $80.2 \%$ & $74.3 \%$ & $82.3 \%$ \\
\hline & Surgical & $84.8 \%$ & $87.0 \%$ & $84.7 \%$ & $85.1 \%$ & $86.2 \%$ & $79.2 \%$ & $83.5 \%$ & $84.0 \%$ & $86.6 \%$ \\
\hline & Caridac & $77.4 \%$ & $85.1 \%$ & $71.0 \%$ & $65.7 \%$ & $70.8 \%$ & $63.5 \%$ & $72.1 \%$ & $64.9 \%$ & $75.3 \%$ \\
\hline & $\mathrm{PCU}$ & $41.8 \%$ & $42.3 \%$ & $59.6 \%$ & $0.0 \%$ & $0.0 \%$ & $42.5 \%$ & $43.6 \%$ & $42.5 \%$ & $43.3 \%$ \\
\hline & Overall & $76.1 \%$ & $79.6 \%$ & $77.7 \%$ & $75.7 \%$ & $78.7 \%$ & $67.7 \%$ & $74.4 \%$ & $70.3 \%$ & $76.3 \%$ \\
\hline Open to trauma & & $88.6 \%$ & $82.1 \%$ & $93.3 \%$ & $96.3 \%$ & $95.1 \%$ & $98.0 \%$ & $94.9 \%$ & $96.7 \%$ & $92.3 \%$ \\
\hline \multirow[t]{5}{*}{ Patients turned away/month } & Medical & 5.7 & 11.3 & 3.3 & 1.7 & 2.9 & 1.0 & 2.8 & 1.7 & 4.4 \\
\hline & Surgical & 4.0 & 8.1 & 2.6 & 1.1 & 2.0 & 0.5 & 2.0 & 1.0 & 3.3 \\
\hline & Caridac & 5.1 & 8.5 & 2.7 & 1.7 & 2.5 & 0.9 & 2.6 & 1.6 & 3.5 \\
\hline & Trauma & 5.4 & 10.2 & 3.3 & 2.2 & 2.7 & 1.0 & 3.0 & 1.8 & 4.1 \\
\hline & $\mathrm{PCU}$ & 1.1 & 1.1 & 7.6 & 27.9 & 27.8 & 1.1 & 1.1 & 1.1 & 1.1 \\
\hline
\end{tabular}




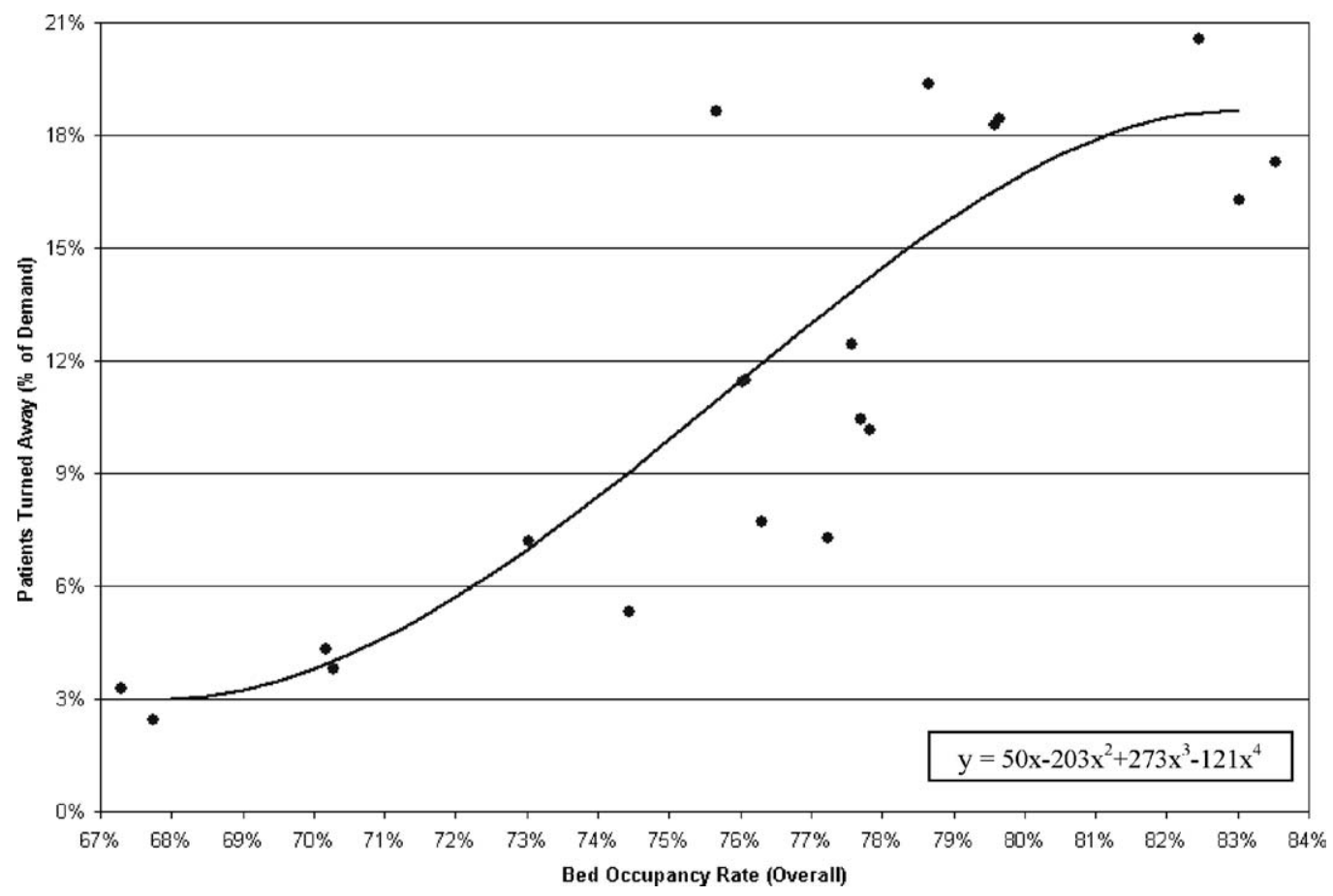

Figure 3. Relationship between bed occupancy rate and patients turned away.

is associated with a significant reconstruction of the second floor ICU space. The results shown here are illustrative of those developed to address sizing of the ICU to meet current demand, seek the appropriate sizing to meet demand in FY 2015 , and illustrate the impact of the increase in demand over time on the effectiveness of a bed configuration.

Under conditions of current patient demand, the smaller bed configurations, such as those represented in the base case and options 1 and 2, appear to provide marginally acceptable performance of the ICU. Option 1 is one of the more effective bed configurations that involve the already funded ICU renovation. This configuration turns away approximately $9 \%$ of patients, with turned away patients reasonably equally balanced in number across patient types. The case nearly complies with the goal that the ICU be open to trauma patients $95 \%$ of the time. It essentially matches the base case with respect to the mix of DRGs needed to support GME activities. (Because this is generally true of the sizing options, shortfalls in DRG mixes are not displayed in the table.)

Given current demand, alternatives involving a larger adult ICU (as illustrated by options 3 and 4) perform noticeably better than the smaller ICU alternatives. Patients turned away are reduced to less than half their levels under the smaller configurations, and all bed configurations examined allow trauma admission $95 \%$ of the time. However, these alternatives also achieve somewhat lower occupancy levels than with the smaller alternatives, suggesting unused capacity.

As demand for the ICU increases over time, the smaller alternatives perform less well (as illustrated in the table with the base configuration and 2015 demand). Under patient demand levels projected for FY 2015, there is a near doubling in patients turned away, and none of the alternatives achieves the $95 \%$ trauma admission threshold.
The larger ICU alternatives (such as options 3 and 4) perform significantly better than the smaller alternatives given FY 2015 demand. Here, the typical bed configuration turns away less than $7 \%$ of patients, barely fails to meet the $95 \%$ trauma admission threshold, and essentially matches the base case with respect to the mix of DRGs needed for GME.

These observations suggest that future ICU needs at WHMC might be met by selecting option 1 or 2 in the near term and transitioning to a larger alternative at some time in the future. Given the projected rate at which demand will increase, none of the smaller alternatives achieves the trauma patient threshold after FY 2007 (as illustrated with option 2 in table 4). This can be viewed as a year by which ICU expansion becomes essential.

Under either near-term or long-term demand assumptions, the PCU appears to be underutilized. For this reason, some bed configurations that trade off PCU beds for more ICU beds result in improved ICU performance. In fact, allowing trauma admissions $95 \%$ of the time appears to require this type of trade off.

Many of the above results can be described in terms of the relationship between bed occupancy rate and ICU congestion (as characterized, for example, by number of patients turned away). Figure 3 is a scatter plot of percent of patients turned away as a function of the overall bed occupancy rate for each of $20 \mathrm{ICU}$ sizing experiments examined in this study. Although the relationship between these two variables is driven by bed mix and demand (which vary among the cases plotted), there is an apparent nonlinear correlation between patients turned away and occupancy rate. (The nonlinearity, suggested by the trend line on the chart, is caused by the constraining limits of the two plotted variables - a finite supply of patients and a maximum possible occupancy rate.) Conges- 
tion increases with occupancy rate, and increases significantly with occupancy rates greater than $75 \%$ of capacity. This suggests that any new or reconfigured ICU that is designed to operate near capacity will have significant access problems.

MHS cost and revenue associated with treating patients who require ICU care appear to be quite insensitive to the specific bed configuration selected. These costs do depend on the overall patient load, and therefore are higher under longterm demand assumptions than in the near term. The costing analysis did not consider the capital investments associated with the different construction options and with the bed alternatives within each.

\subsection{Closure policy}

Closure policy refers to the rules by which the ICU is closed to one or more types of patients when near capacity, to help ensure that the ICU will remain open to other patient types. To explore the impact of alternative closure policies on ICU operations, we investigated two policies that have been employed in the past at WHMC. The first involves closing the ICU to medicine patients when only one ICU bed (of any of the three big bed types) remains unoccupied; the second involves closing the ICU to trauma patients when only one ICU bed remains unoccupied.

The analysis indicated that these policies have little effect on the total number of patients turned away and on bed occupancy. A closure policy that limits medicine patients when the ICU is nearly full will increase the percent of time that the unit is open to trauma patients, because it rejects arriving medicine patients in favor of trauma (and other) patients who have not yet arrived. This suggests that use of a closure policy might be a viable strategy for ensuring compliance with the trauma threshold in situations that otherwise fall slightly short of the $95 \%$ level.

\subsection{Partitioning policy}

Partitioning policies limit the types of patients that can be assigned to certain types of beds. Such a policy might require that medical patients be assigned only to medical beds, surgical patients only to surgical beds, etc. These policies help align patients with the specific type of care required but restrict certain admissions dependent upon certain types of ICU beds. Most of the model experiments conducted in this study assumed that each arriving patient of a given type had a first, second, and third choice for a bed type. Any patient requiring a big bed would likely be admitted to the ICU, although possibly in a low priority bed type if given the availability of any ICU bed. With this lack of bed partitioning, the mix of big beds by type in a bed configuration has no impact on overall occupancy rate, number and mix of patients turned away from big beds, nor percent of time that the ICU is open to trauma patients. However, bed priorities and mix of arriving patients by type do cause cardiac beds to be somewhat less utilized than medical and surgical beds. Model experiments that did impose bed partitioning improved alignment of patients with
Table 5

Impacts of a medical deployment.

\begin{tabular}{|c|c|c|c|c|c|c|}
\hline \multirow[t]{4}{*}{ Case } & \multirow{4}{*}{$\begin{array}{c}\text { Bed } \\
\text { configu- } \\
\text { ration }\end{array}$} & \multicolumn{5}{|c|}{ Deployed? } \\
\hline & & \multirow{3}{*}{$\frac{\text { No }}{\text { Option } 1}$} & \multicolumn{4}{|c|}{ Yes } \\
\hline & & & \multirow{2}{*}{$\begin{array}{c}\text { Reduce } \\
\text { all bed } \\
\text { types }\end{array}$} & \multirow[t]{2}{*}{$\begin{array}{l}\text { Close } \\
\text { PCU }\end{array}$} & \multicolumn{2}{|c|}{$\begin{array}{c}\text { Close PCU, } \\
\text { close to medicine }\end{array}$} \\
\hline & & & & & With 1 & With 2 \\
\hline \multirow{4}{*}{ Available beds } & Medical & 11 & 8 & 10 & 10 & 10 \\
\hline & Surgical & 12 & 8 & 8 & 8 & 8 \\
\hline & Cardiac & 10 & 8 & 8 & 8 & 8 \\
\hline & PCU & 3 & 3 & 0 & 0 & 0 \\
\hline \multirow{5}{*}{$\begin{array}{l}\text { Bed occupancy } \\
\quad \text { rates }\end{array}$} & Medical & $81.2 \%$ & $85.3 \%$ & $82.4 \%$ & $82.0 \%$ & $81.1 \%$ \\
\hline & Surgical & $84.7 \%$ & $84.0 \%$ & $84.5 \%$ & $84.3 \%$ & $84.7 \%$ \\
\hline & Cardiac & $71.0 \%$ & $81.3 \%$ & $78.5 \%$ & $77.9 \%$ & $75.6 \%$ \\
\hline & PCU & $59.6 \%$ & $58.1 \%$ & $0.0 \%$ & $0.0 \%$ & $0.0 \%$ \\
\hline & Overall & $77.7 \%$ & $80.7 \%$ & $81.8 \%$ & $81.4 \%$ & $80.5 \%$ \\
\hline Open to trauma & & $93.3 \%$ & $81.6 \%$ & $86.1 \%$ & $89.7 \%$ & $92.5 \%$ \\
\hline \multirow{5}{*}{$\begin{array}{l}\text { Patients turned } \\
\text { away/month }\end{array}$} & Medical & 3.3 & 8.9 & 6.3 & 11.6 & 15.5 \\
\hline & Surgical & 2.6 & 6.4 & 5.0 & 3.8 & 2.8 \\
\hline & Cardiac & 2.7 & 7.0 & 5.6 & 4.2 & 2.6 \\
\hline & Trauma & 3.3 & 6.2 & 4.8 & 3.6 & 2.5 \\
\hline & PCU & 7.6 & 7.8 & 27.9 & 27.9 & 27.9 \\
\hline \multirow{4}{*}{$\begin{array}{l}\text { Shortfall in } \\
\text { DRG mix }\end{array}$} & Medical & $0 \%$ & $22 \%$ & $18 \%$ & $30 \%$ & $38 \%$ \\
\hline & Surgical & $0 \%$ & $10 \%$ & $5 \%$ & $4 \%$ & $3 \%$ \\
\hline & Cardiac & $0 \%$ & $11 \%$ & $6 \%$ & $6 \%$ & $4 \%$ \\
\hline & Trauma & $0 \%$ & $31 \%$ & $26 \%$ & $24 \%$ & $22 \%$ \\
\hline
\end{tabular}

their preferred bed types, but with a concomitant reduction in access to the ICU, as measured by patients turned away.

\subsection{Deployment impacts}

A major medical deployment reduces the personnel available to staff the ICU, resulting in a requirement to close some beds. It simultaneously decreases the demand for use of the ICU because of reduced capacity in other areas of the hospital that feed the ICU and possibly a temporary reduction in the population served by the ICU. We investigated these effects using ICU bed availability levels and demand experienced during the deployment of medical personnel from WHMC to Afghanistan in late 2001. We then explored bed closure and policy alternatives that might mitigate the impacts of the deployment on ICU operations.

A total of five cases were investigated, as summarized in table 5:

- The original option 1 with no deployment served as the baseline.

- Two deployment cases were used to explore alternative ways to reduce ICU capacity to accommodate the reduction in available staff.

- To attempt to improve ACS compliance during a deployment, two alternative deployment cases were run which imposed closure policies such that beds were closed to medicine when one and two beds remained unoccupied.

As illustrated in the second column of results in the table, a major medical deployment can have serious negative ef- 
fects on the continued operation of the ICU in spite of the fact that demand declines somewhat during periods of deployment. These negative effects include high occupancy rates and corresponding large increases in the number of patients turned away, a significant degradation in the percent of time the unit remains open to trauma patients, and large reductions from the DRG mix required to support the training of residents. Closing the PCU under such circumstances alleviates all of these problems somewhat with respect to operation of the big beds (but requires that all patients who would otherwise be admitted directly to the PCU be treated in some other setting). Instituting a closure policy that closes the ICU to medicine patients provides some improvement in the time closed to trauma patients and improves the DRG mix in all clinical areas except medicine without significantly increasing the rate at which patients are turned away from the ICU. However, all deployment cases examined in this study result in degraded residency experiences, especially in the medical and trauma clinical areas.

\section{Summary}

The case study described here illustrates some important characteristics of the successful use of models and data to support MHS optimization:

- The modeling and analysis effort must involve the staff of the facility under analysis to ensure appropriate assumptions are adopted, important issues are analyzed, and the model and its results are embraced.

- The effort must include model validation to help ensure that results are both correct and accepted by decision makers.

- Model effectiveness requires adequate data appropriately processed to help characterize the processes (such as demand for services) being simulated.

- Model development should focus on representing the critical elements (such as numbers of staffed beds by type) to answer a specific question, and avoid capturing unnecessary details.

- Because model development is a relatively costly endeavor, model design should be generalized for potential adaptation to other settings.

- Analysis efforts should focus on insights that follow from understanding why the model produced the observed results.
Analysis efforts with these characteristics can provide useful observations that focus on important issues, data collection efforts that emphasize measurement of the most important characteristics of the processes being studied, and models with utility beyond the specific studies for which they were developed. This case study produced important insights into sizing and operation of the WHMC ICU, data whose continued collection and analysis can be used to monitor the continued efficiency of the ICU, and a model that will support analysis of ICU sizing and policy issues elsewhere within the MHS.

\section{Acknowledgements}

The opinions or assertions herein are those of the authors and do not necessarily reflect the view of the Department of Defense.

\section{References}

[1] United States Congress, National Defense Authorization Act for FY 2001, Section 733 (Washington, DC, 2001).

[2] W. Cahill and M.L. Render, Dynamic simulation modeling of ICU bed availability, in: Proceedings of the 1999 Winter Simulation Conference (1999) pp. 1573-1576.

[3] J.C. Lowery, Simulation of a hospital's surgical suite and critical care area, in: Proceedings of the 1992 Winter Simulation Conference (1992) pp. 1071-1087.

[4] S.V. Williams, How many intensive care beds are enough? Critical Care Medicine 11 (1983) 412-416.

[5] F. Zilm, D. Arch and R.B. Hollis, An application of simulation modeling to surgical intensive care bed need analysis in a university hospital, Hospital and Health Services Administration (1983) 82-101.

[6] D.W. Yergens, C.J. Doig and J.D. Sandham, Computer simulation modeling for predicting ICU bed requirements in a tertiary care hospital, Clinical and Investigative Medicine 18(4) (1995) suppl: B23.

[7] S.C. Kim, I. Horowitz, K. Young and T.A. Buckley, Analysis of capacity management of the intensive care unit in a hospital, European Journal of Operational Research 115 (1999) 36-46.

[8] J.C. Ridge, S.K. Jones, M.S. Nielsen and A.K. Shahani, Capacity planning for intensive care units, European Journal of Operational Research 105 (1998) 346-355.

[9] J.M. Lamiell, Modeling intensive care unit census, Military Medicine 160 (1995) 227-232.

[10] G. Miller, E. Forkner, A. Crouter and S. Randolph, Model-Based Analysis of Long-Term Disease Management (Vector Research, Inc., Ann Arbor, MI, 2002).

[11] J.C. Lowery, Multi-hospital validation of critical care simulation model, in: Proceedings of the 1993 Winter Simulation Conference (1993) pp. 1207-1215. 